\title{
WyOMING InBRE COMMUNITY COLLEGE NETWORK RETREAT AMK RANCH (UW-NPS RESEARCH CENTER)
}

\section{R. SCOTT SEVILLE $\uparrow$ WyOMING INBRE PROGRAM COORDINATOR \\ UNIVERSITY OF WYOMING ^ LARAMIE}

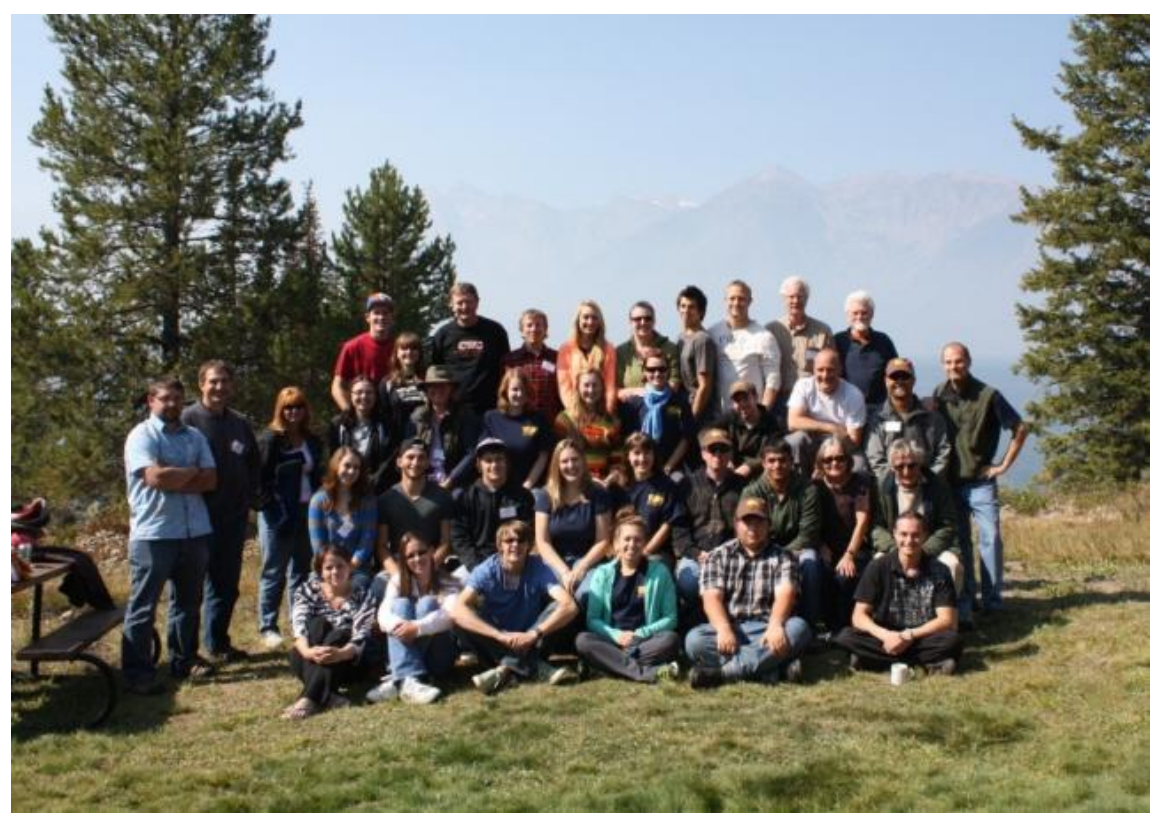

Students and Faculty from across the state. (R.S. Seville, 2012).

\section{$\uparrow$ MEETING OVERVIEW}

The Wyoming INBRE Community College network meets yearly to present research taking place throughout the state. The focus is on undergraduate research taking place at the community colleges throughout Wyoming. The students present on their individual projects and faculty present on their research and partnerships they have formed. This is also a time for students and faculty to collaborate on projects statewide.

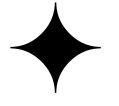

\section{$\downarrow \quad$ PROGRAM BACKGROUND}

The University of Wyoming is one of 22 institutions funded by the National Institutes for Health IDeA Networks for Biomedical Research Excellence (INBRE) Program. INBRE funding is intended to enhance biomedical research capacity, expand and strengthen the research capabilities of biomedical faculty, and provide access to biomedical resources for promising undergraduate students throughout the eligible states.

The Wyoming IDeA Networks for Biomedical Research Excellence (INBRE) Program is 
funded by the National Institutes for Health National Center for Research Resources (NCRR). The ultimate goal the INBRE program is to promote the development, coordination, and sharing of research resources and expertise that will expand research opportunities and increase the number of competitive investigators in IDeA-eligible states. INBRE programs are intended to enhance the caliber of scientific faculty at research institutions and undergraduate schools, thereby attracting more promising students to these organizations.

The goals of Wyoming INBRE are to:

1. Establish a multidisciplinary research network with scientific foci that will build and strengthen biomedical research at UW and its partner institutions (Wyoming Community Colleges);

2. Provide research support to faculty, postdoctoral fellows and graduate students;

3. Create a "pipeline" for undergraduate students at UW and Wyoming community colleges to foster advanced education and training in the biomedical sciences;

4. Provide outreach activities for UW and community college students that are part of the university's INBRE network;

5. Enhance science and technology knowledge of the state's workforce;

6. Expand Wyoming research opportunities across the region.

To accomplish these goals Wyoming INBRE has established a number of programs designed to provide support for activities at all levels of education that enhance biomedically related research, training, education, and recruitment. Support for research is targeted at projects and programs that address health issues important to Wyoming residents that range from benchtop research to clinical, translational, or community based investigations. Two current areas of particular research interest are cardiovascular health and Type 2 diabetes. Support is currently provided to selected junior investigators on the UW Laramie campus developing projects related to the two focal areas. Additional support is available for researchers through the annual INBRE Pilot Grant Program, INBRE Graduate Assistantship Program, INBRE Undergraduate Support Grant Program, and the INBRE UW- CC Collaborative Grant Program. Proposals for projects related to cardiovascular health and Type 2 diabetes are encouraged but projects focused on other health related issues will be considered. In addition INBRE is interested in partnering with other UW units to provide faculty start-up support for biomedically targeted faculty hires by colleges and departments and for major equipment purchases that build UWs research infrastructure.

To support biomedically related education INBRE has several programs available to UW faculty in Laramie and at Wyoming Community Colleges. Support is provided to participating Wyoming Community College faculty to develop research projects on their campuses that can engage students in the process of science and potentially attract them into biomedically related degree programs. The Outreach Videoconference System was developed and is maintained in part with INBRE support and is available for use for courses, seminars, and meetings at no charge for INBRE and other biomedically related uses. Other programs focused on education and recruitment include: INBRE Transition Scholarship Program that supports outstanding community college students transfering to the University to pursue baccaulareate degrees; INBRE Transition Course Program that supports development of distance delivered upper division courses for students across Wyoming pursuing baccalaureate degrees in the life sciences; INBRE Bioinformatics Summer Institute for students interested in pursuing advanced education and training in bioinformatics; and the INBRE Community College Videoconference Seminar Series that provides monthly seminars to community college faculty and students from UW, Community College and visiting scientists. In addition INBRE is developing projects for K-12 faculty and students that will enhance their knowledge of educational and career opportunities in biomedicine. INBRE is also interested in partnering with other UW and Community College units to support projects focused on public health and health awareness.

Last, Wyoming INBRE is working with other western INBRE states to develop regional opportunities for research collaborations and educational opportunities for students and faculty. In the future support will be available for researchers pursuing collaborative projects and educational opportunities with colleagues from INBRE programs in Alaska, Idaho, Montana, Nevada, New Mexico, Montana and the University of Washington Institute for Translational Sciences (ITHS), University of New Mexico Clinical and Translational Sciences Program (CTSA), and the University of Colorado Medical Center CTSA. Wyoming INBRE is working with these programs to foster innovative new decentralized regional clinical and translational research programs that leverage and build on resources throughout the 
Western region. To achieve this goal, Wyoming INBRE is interested in promoting research programs that are community based and/or patient-centered.

For questions or additional information contact Dr. Jun Ren ( jren@uwyo.edu), INBRE Program Director or Scott Seville ( sseville@uwyo.edu), INBRE Program Coordinator.

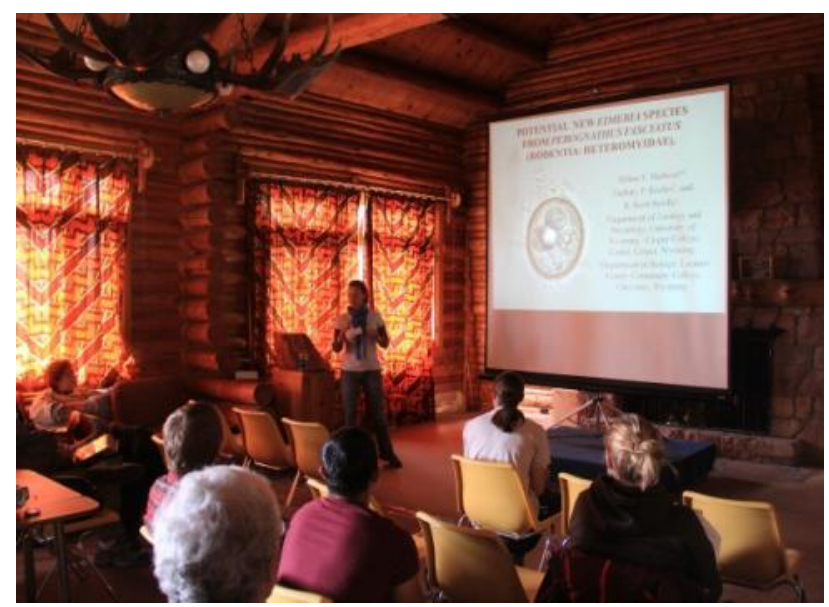

Delina Barbosa, student at University of Wyoming/Casper College Center, presents. (R.S. Seville, 2012).

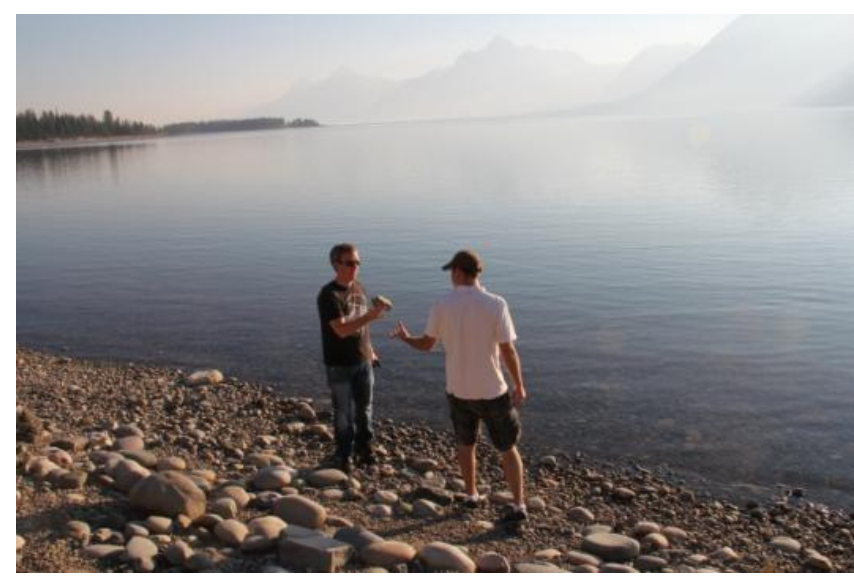

Students enjoy some time exploring. (Barbosa, 2012).

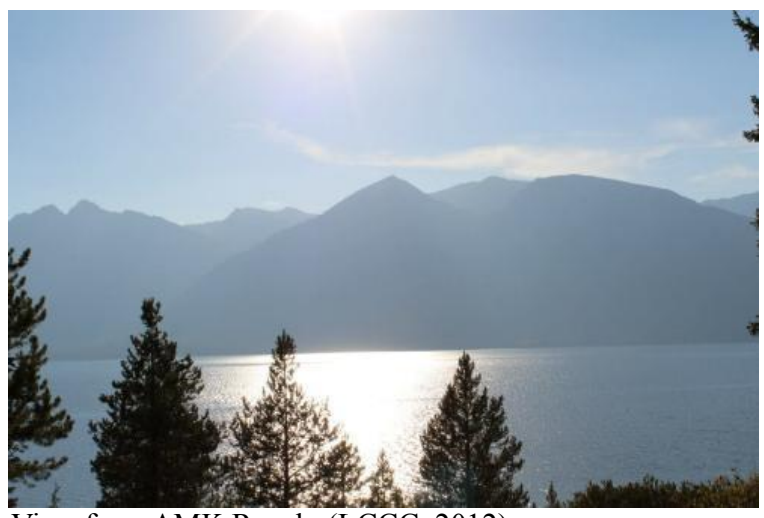

View from AMK Ranch. (LCCC, 2012).

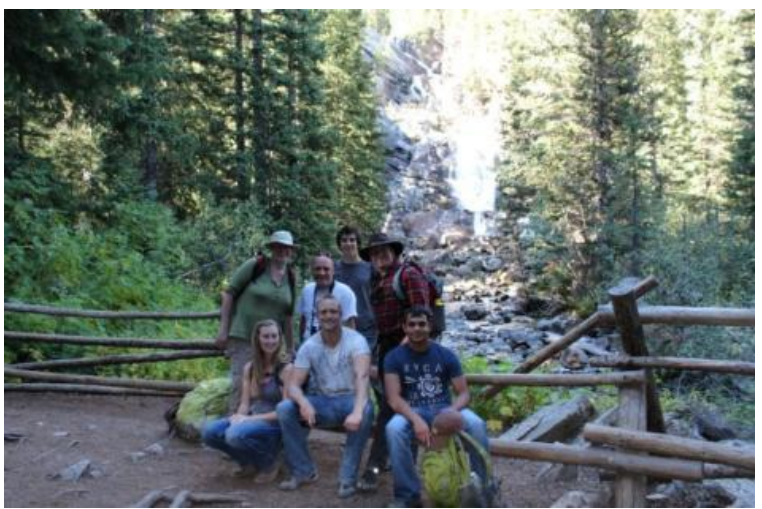

Students and faculty out on a hike. (LCCC, 2012).

This project was supported by grants from the National Center for Research Resources (5P20RR016474-12) and the National Institute of General Medical Sciences (8 P20 GM103432-12) from the National Institutes of Health. 